\title{
UTILIZATION OF SIMULATIONS TO OPTIMIZE OF STEEL FLOW IN THREE STRAND T-SHAPE TUNDISH
}

\author{
${ }^{1}$ Lukáš FOGARAŠ, ${ }^{1}$ Branislav BUL'KO, ${ }^{1}$ Peter DEMETER, ${ }^{1}$ Slavomír HUBATKA, ${ }^{1}$ Vladimír ŠABíK \\ ${ }^{1}$ Institute of metallurgy, Faculty of Materials, Metallurgy and Recycling Department of Metallurgy, Technical \\ University of Košice, Košice, Slovakia,EU, lukas.fogaras@tuke.sk
}

https://doi.org/10.37904/metal.2021.4096

\begin{abstract}
This article is focused on the optimization of the flow of steel in a symmetrical three-strand T-shaped tundish based on the change of its internal equipment. Since the investigated tundish has three outlet strands, it is very important to properly adjust its internal volume to achieve optimal flow and final steel purity. The main goal was to optimize the distribution of molten steel in a T-shaped tundish during the transition area. At the transition area, a new steel grade is started to be tapping into the tundish, which is filled with the previous steel grade. The goal was achieved by minimizing differences of the main investigated parameters, residence time between the middle and lateral casting strands. By reaching the lowest possible value of the maximum and the highest value of the minimum residence time, the tundish has favorable conditions for shortening the transition area, refining, cleanliness, and homogeneity of the steel. Ansys Fluent 17.2 Computational Fluid Dynamics (CFD) software was used to proposal the solution of the flow problem. The monitored flow changes were realized by deflecting the outlet openings in the dam of the tundish. Also, mathematical simulations were verified on a physical water model of a symmetrical T-shaped tundish at a scale of 1:2 to verify the accuracy of the simulation. Measurements were evaluated numerically and graphically in the form of $\mathrm{C}$-curves and residence times. Residence time was recorded by monitoring the change in conductivity on the input and output probes during steady flow in the tundish under specified conditions using the water model.
\end{abstract}

Keywords: Tundish, metallurgy, modelling, simulation, residence time

\section{INTRODUCTION}

The tundish is one of the most important component of a continuous casting process which is necessary to achieve the required cleanliness and quality of steel and primarily serves as a reservoir and distributor of liquid steel in the casting process [1]. The aim of the tundish is to provide the steel with the longest possible time required to remove the inclusions from the steel into the slag [2-4]. This paper deals with the issue of steel flow in a three-strand symmetrical T-shaped tundish. For the validity of the tundish model, obtaining the RTD (Residence Time Distribution) curves for all casting strands is of fundamental importance. The residence time values are used to assess the change time of the transition area. Since this type of tundish has three outlets, the biggest problem is to achieve the smallest possible differences in residence times between the middle casting strand (CS) No.2 and lateral casting strands (CS) No.1,3. The minimum residence time (Tmin.) is an indicator of the shortest time for which the new quality concentration is recorded at the outlet of the tundish [5]. The maximum residence time (Tmax.) is an indicator of the time period during which the concentration changes completely and the previous quality is replaced by a new one (the concentration value is $100 \%)$. C-curves are used as an evaluation means to characterize the flow during a steady-state casting regime [6]. The Figure 1 shows a graphical evaluation of the mathematical simulation of steel flow in a three-strand T-shaped tundish in the form of C-curves. As we can see, the green line which represents the middle (CS) No.2 reaches the minimum and maximum residence time significantly faster than the other strands. Deviations of the middle 
strand from the lateral strands were at min. residence time of $50 \%$ and a max. residence time of $120 \%$. This is an undesirable phenomenon which, could cause the reducing purity and homogeneity of the steel and also cause excessive wear of the tundish lining by dynamic flow. In an effort to avoid such an undesirable phenomenon, it is possible to replace a financially and time-consuming experiment with the implementation of mathematical and physical modeling. Using mathematical simulations, it is possible to create a design of the required experimental model for its further investigation. Through mathematical and physical modeling, the internal equipment of the tundish was optimized in order to minimize the differences in residence times [7]. The flow changes were performed by optimizing the outlet openings of the dam in the tundish, to achieve a minimum difference between the residence times of the middle and lateral strands [8]. Several simulations were performed with different deflections of the outlet openings in the tundish dam at angles of $8^{\circ}, 12^{\circ}$ and $16^{\circ}$ from their standard configuration. The dam in the tundish is used to distribute steel from one part of the tundish to another. The application of the method of mathematical simulation of the process requires verification of the correctness of the result due to the inaccuracy and uncertainty of the result. Therefore, the method of mathematical simulation was supplemented by a physical model of a symmetrical three-strand T-shaped tundish at a scale of 1:2.

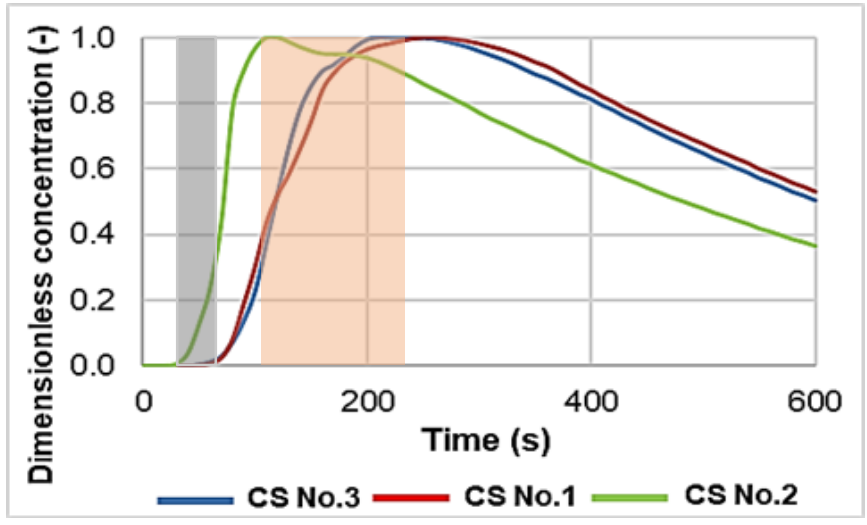

Figure 1 Comparison of differences max. (orange area) / min. (gray area) residence time between 2nd and $1 \mathrm{st}, 3 \mathrm{rd}(\mathrm{CS})$

\section{RESEARCH FINDINGS}

The mathematical model proposed in the ANSYS Fluent 17.2 program analyzed 3 configurations of the physical water model of a symmetrical T-shaped tundish. Subsequently, the tundish model was discretized to a computational mesh in the Ansys Meshing program. Computational mesh was analyzed by quality control and based on SKEWNESS and ORTHOGONALITY criteria, which define the quality of the mesh according to Figure 2. The quality of the cells indicates the degree of shape deformation of the cells compared to its ideal shape [9]. The quality of the mesh affects the length of the calculation and the quality of the result. The qualitative parameters of the mesh used are described as follows. According to the mesh quality evaluation criteria, the computational mesh achieved "good" results for orthogonality and skewness, with most mesh cells having "very good / excellent" properties. Minimum orthogonal mesh quality: $3.65227 \mathrm{e}^{-1}$. The number of defined boundary layers was 15 for the mesh used. Skewness mesh quality: $4.75931 \mathrm{e}^{-1}$.

\begin{tabular}{|c|c|c|c|c|c|}
\hline Great & Very good & Good & Acceptable & Bad & Unacceptable \\
\hline $0-0.25$ & $0.25-0.50$ & $0.50-0.80$ & $0.80-0.94$ & $0.95-0.97$ & $0.97-0.10$ \\
\hline \multicolumn{6}{|c|}{ Qualitative spectrum for the ORTHOGONAL quality criterion } \\
\hline Unacceptable & Bad & Acceptable & Good & Very good & Great \\
\hline $0-0.001$ & $0.001-0.14$ & $0.15-0.20$ & $0.20-0.69$ & $0.7-0.95$ & $0.95-1.00$ \\
\hline
\end{tabular}

Figure 2 Qualitative mesh criterion [9] 
The mathematical model of the tundish was modeled as a non-stationary process, for the possibility of analysis of C-curves. The non-stationary model shows the state of the system in individual time periods corresponding to the set time step. The method of evaluating C-Curves on the basis of concentration was performed using a dimensionless concentration value in the range of $0-1$ (where 0 represents $0 \%$ and 1 represents $100 \%$ of the concentration value). Between the values of the minimum and maximum residence time is the transition period of casting and the value of the dimensionless concentration represents the percentage of the new quality. The boundary conditions of the model were defined on the basis of the analysis of the physical water model of the tundish. (Boundary conditions are physical quantities defined at the boundaries of the computational mesh, which express the physical nature of the modeled event). The main boundary condition for the inlet was the mass flow of water into the water model, which was set as a constant (the value did not change over time). Tracer injection into the model was defined through a time-dependent function that was included in the water mass flow. The injection time was 6 seconds in an amount of $150 \mathrm{ml}$. For the output of the model, the boundary condition Outflow was set, which redistributes the mass flow to several places as the water model has 3 outlets. The Figure 3 is a graphical representation of the investigated tundish and its description. The walls of the model were defined by the boundary condition Wall, which presents the fixed walls of the computational area.

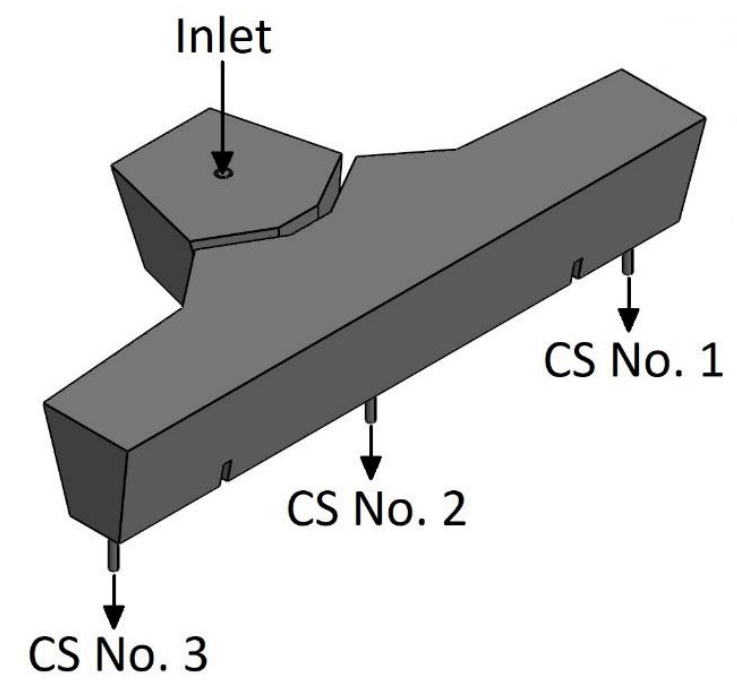

Figure 3 Geometry 3 of a T-shaped tundish and its parameters

The parameters entered in the solver were as follows. Non-stationary calculation was used due to the need to plot the C-curve. It was considered with the action of gravity in the z-axis $=-9.81 \mathrm{~m} \cdot \mathrm{s}^{-2}$. Used model Realizable $k-\omega$ SST. Liquid water was used as the material. For boundary conditions, the input was defined as Mass Flow rate. The solution method was Simple, initialization from all zones. Shear friction on the walls was not considered. The number of iterations was 50 with a time step of 600 per 1 second.

The used physical model corresponds to a symmetrical T-type tundish with tube protection, three outlet strands, equipped with a standard impact plate and barriers to direct the flow. The mentioned model is a part of the laboratory of simulation of flow processes located at the Technical University in Košice, Department of Metallurgy, Department of Metallurgy and Foundry. The laboratory is focused on the investigation of the flow of liquid steel on a continuous casting equipment [10]. Steel is replaced by water in the physical model, the similarity of the kinematic viscosity of steel at $1600^{\circ} \mathrm{C}$ and water at $20^{\circ} \mathrm{C}$ is used Table 1 . The flow is simulated by an injection solution, the concentration of which is sensed by conductivity probes at the inlet and outlet of the tundish. To achieve visualization of the flow of the injected medium in the volume of tundish, hyper manganese $\mathrm{KMnO}_{4}$ is added to the injected solution, which colors the strand, which allows the recognition of the flow pattern of the tracer [4]. 
Table 1 Comparison of steel and water properties

\begin{tabular}{|l|c|c|}
\hline Physical value & Steel $1600^{\circ} \mathrm{C}$ & Water $20^{\circ} \mathrm{C}$ \\
\hline Density $\left[\mathrm{kg} \cdot \mathrm{m}^{-3}\right]$ & 7014 & 1000 \\
\hline Surface tension $\left[\mathrm{N}^{\left.-\mathrm{m}^{-1}\right]}\right.$ & 1.6 & 0.073 \\
\hline Dynamic viscosity $[\mathrm{Pa} \cdot \mathrm{s}]$ & 0.0064 & 0.001 \\
\hline Kinematic viscosity $\left[\mathrm{m}^{2} . \mathrm{s}^{-1}\right]$ & $0.913 .10^{-6}$ & $1.00 .10^{-6}$ \\
\hline
\end{tabular}

With the intention of extending the residence time of flow (CS) No.2, several simulations were performed with different deflections of the outlet openings in the tundish dam at angles of $8^{\circ}, 12^{\circ}$ and $16^{\circ}$ from their original perpendicular axis. From the point of view of residence times on individual casting flows, deflecting the holes by $8^{\circ}$ away from flow no. 2 seems to be the most suitable variant. At larger deflection angles, there was already a deformation of the C-curve at the middle flow, which is not desirable Figure 4 . The above simulation is compared with the standard $90^{\circ}$ (currently used) configuration of the tundish Figure 5.

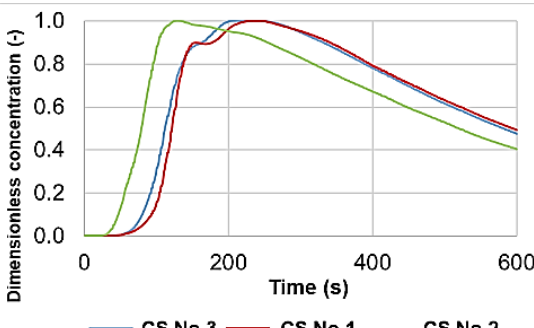

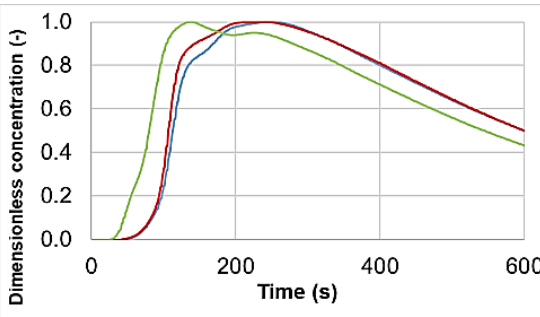

CS No.3 CS No.1 CS No.2

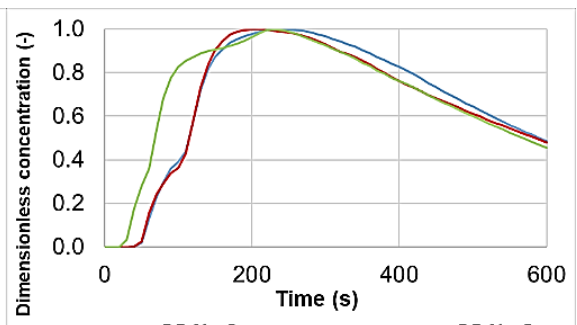

CS No.3 - $\operatorname{cs~N0.1-~CS~No.2~}$

Figure 4 Comparison of results of mathematical simulations of C-curves at deviations from left $8^{\circ}, 12^{\circ}, 16^{\circ}$
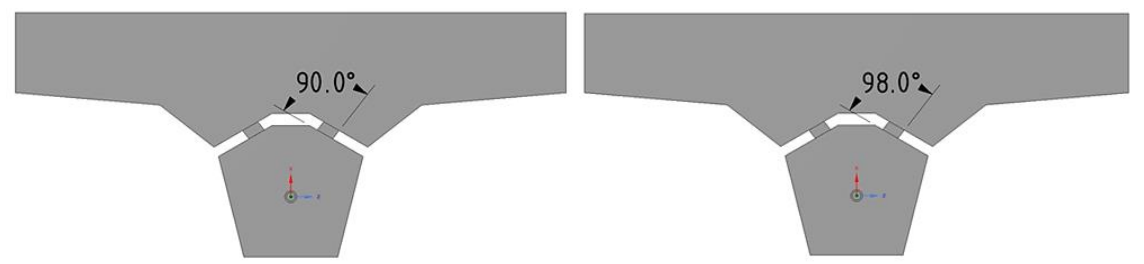

Figure 5 Standard $90^{\circ}$ and optimized tundish configuration with $+8^{\circ}$ deflection

\section{RESULTS AND DISCUSSION}

For the standard and optimized configuration of the tundish, three measurements were performed in physical and mathematical modeling under the same conditions and settings Table 2, from which the average values of the minimum and max. residence time for the left, middle and right casting strands were evaluated. For visual comparison, the water solution of $\mathrm{KMnO}_{4}$ hyper manganese was used and observations were recorded at three-time intervals depending on the largest differences observed. The measurement is started from the moment the tracer is injected.

Table 2 Setting of the tundish for the needs of measuring C-Curves

\begin{tabular}{|l|c|}
\hline \multicolumn{2}{|c|}{ Tundish flow configuration } \\
\hline Mode & Steady state mode \\
\hline Tundish inlet & $24\left[l . \mathrm{min}^{-1}\right]$ \\
\hline Tundish outlet & $8\left[\mathrm{lmin}^{-1}\right]$ \\
\hline Level height & $300 \mathrm{~mm}$ \\
\hline Amount of tracer & $150 \mathrm{ml}$ \\
\hline Number of measurement repetitions & 3 \\
\hline
\end{tabular}


In the following graphs is the evaluation of measurements in the standard (left graph) and optimized configuration (right graph) in the form of C-curves. In Figure 6 the left graph shows the results of the standard configuration, and the right graph shows the results of the optimized configuration with a deviation of $8^{\circ}$. The Figure 7 shows the results of verification of the mathematical simulation by a physical model, the distribution of the graphs is same to Figure 6.
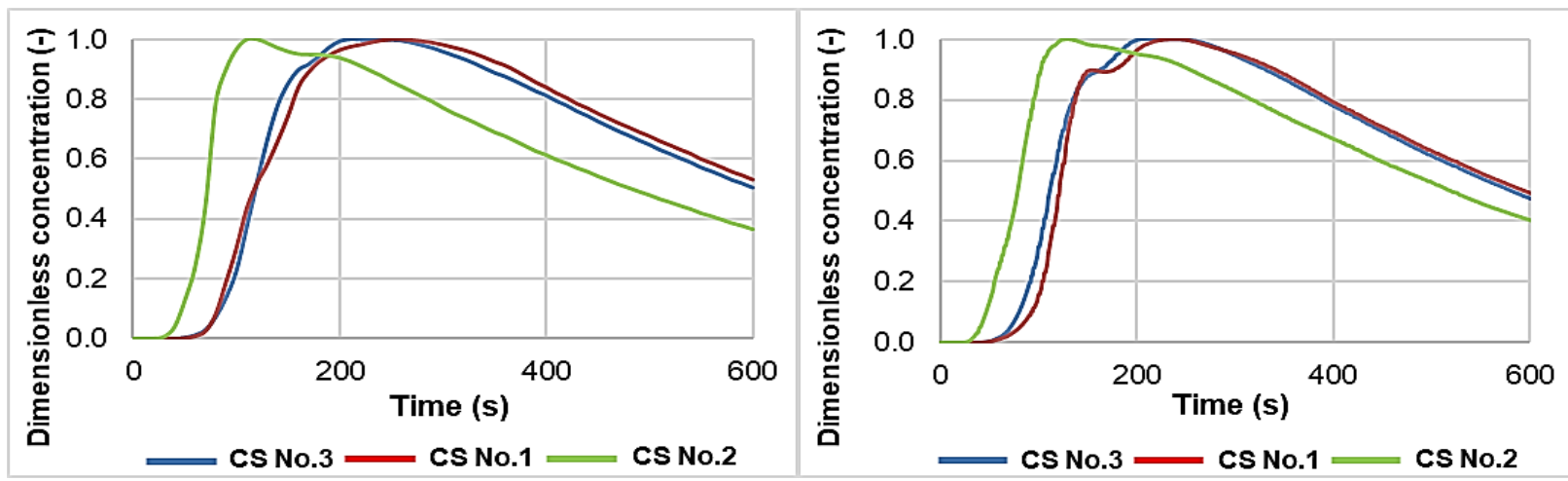

Figure 6 Results of mathematical simulation: left (standard configuration), right (optimized configuration $+8^{\circ}$ )
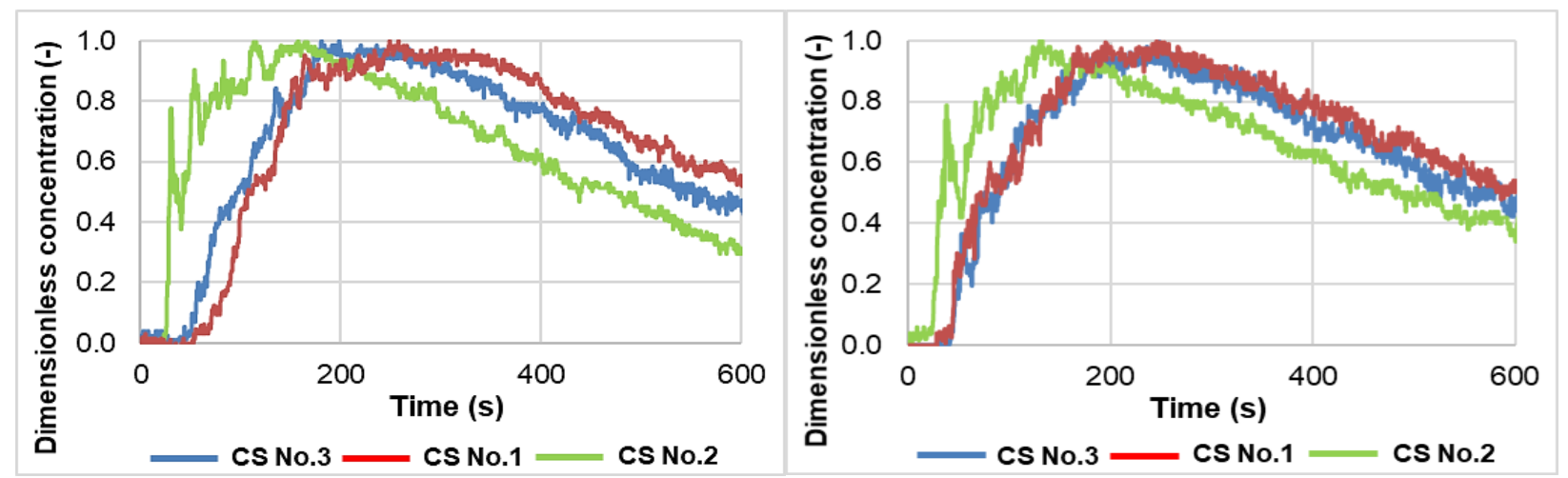

Figure 7 The results of physical simulation left (standard configuration), right (optimized configuration $+8^{\circ}$ )

The shape of the C-curves and the residence time values are very similar for both configurations and models. It is clear from the graphs and tables that the verification of mathematical simulations by a physical model confirmed the correctness of the investigated optimization of the deflection of the outlet openings in the tundish dam. The differences in residence times between casting flows were visibly shortened after optimization on both the physical and mathematical models. The optimized deflection of $8^{\circ}$ shortened the residence times by approx. 18\%. The distribution of residence times between the individual casting strands Figure 6 shows that the shortest time is the middle flow (CS) No.2. This result was also confirmed by physical simulations Figure 7. In Table 3,4 the specific measured values of minimum and maximum residence times of mathematical and physical model are shown. The tables also show the percentage differences in residence times for both configurations.

Table 3 Resulting values of residence times of mathematical simulations

\begin{tabular}{|l|c|c|c|c|c|c|}
\hline \multicolumn{1}{|c|}{ Casting strand (CS) MATH. } & \multicolumn{2}{c|}{ (CS) No.3 } & \multicolumn{2}{c|}{ (CS) No.2 } & \multicolumn{2}{c|}{ (CS) No.1 } \\
\hline Parameter [s] & $T_{\min }$ & $T_{\max .}$ & $T_{\min .}$ & $T_{\max .}$ & $T_{\min }$ & $T_{\max }$ \\
\hline Residence time - Standard & 34.7 & 195.6 & 22.6 & 155.7 & 55.5 & 244.8 \\
\hline Residence time - Diversion $8^{\circ}$ & 42.3 & 240.5 & 28.5 & 125.3 & 48.7 & 242.3 \\
\hline Percentage difference & $+22 \%$ & $+23 \%$ & $+26.1 \%$ & $-19.5 \%$ & $-12.3 \%$ & $-1 \%$ \\
\hline
\end{tabular}


Table 4 Resulting values of residence times of physical simulations

\begin{tabular}{|l|c|c|c|c|c|c|}
\hline \multicolumn{1}{|c|}{ Casting strand (CS) PHYS. } & \multicolumn{2}{c|}{ (CS) No.3 } & \multicolumn{2}{c|}{ (CS) No.2 } & \multicolumn{2}{c|}{ (CS) No.1 } \\
\hline Parameter [s] & $T_{\min .}$ & $T_{\max .}$ & $T_{\min .}$ & $T_{\max .}$ & $T_{\min .}$ & $T_{\max .}$ \\
\hline Residence time - Standard & 35.4 & 180.6 & 22.7 & 157.3 & 53.2 & 248.6 \\
\hline Residence time - Diversion 8 $^{\circ}$ & 41.8 & 247.7 & 24.8 & 129.7 & 42.1 & 245.5 \\
\hline Percentage difference & $+18.1 \%$ & $+37.2 \%$ & $+9.3 \%$ & $-17.5 \%$ & $-21 \%$ & $-1.2 \%$ \\
\hline
\end{tabular}

\section{CONCLUSION}

Based on the results of verification of mathematical simulations by physical model, it is possible to state the success of the proposed deviation of the outlet openings in the tundish dam by $8^{\circ}$. The deflection would lead to a more even flow in the tundish, as the residence time of the middle strand approached strands 1 . and 3. Improving the residence times by $18 \%$ means shortening the transition area which improving steel quality, higher cleanliness of cast steel and less wear of refractory lining of tundish. Applying this configuration in practice would reduce the unusable transition product. Higher cleanliness of steel is directly proportional to its quality and lower wear of the refractory lining would lead to a reduction in the cost of its repair and eventual replacement. All factors would be positively reflected in the increase in production of quality steel and profit from production.

\section{ACKNOWLEDGEMENTS}

\section{Authors are grateful for funding by VEGA project 1/0212/21.}

\section{REFERENCES}

[1] SMIL, V. Still the Iron Age: Iron and Steel in the Modern World. Butterworth-Heinemann, 2016.

[2] PALLOTTA S.p.A, Refractories for continuous casting tundish. [Online]. 2018. [viewed: 2021-06-21]. Available from: http://www.pallottaspa.it/pdf/brochures/Continuous-Casting-Tundish.pdf.

[3] SAHAI, Y. Tundish technology for clean steel production. Singapore: Hackensack, NJ: World Scientific, 2008.

[4] KOWITWARANGKUL, P., HARNSIHACACHA, A. Tracer injection simulations and RTD analysis for the flow in 3strands steelmaking tundish. Key Engineering Materials. [Online]. 2016, vol. 728, pp. 72-77. Available from: https://doi.org/10.4028/www.scientific.net/KEM.728.72.

[5] HARNSIHACACHA, A., PIYAPANEEKOON, A., KOWITWARANGKUL, P. Physical water model and CFD studies of fluid flow in a single strand tundish. Materials Today. [Online]. 2018, vol. 5, no. 3, pp. 53-88. Available from: https://doi.org/10.1016/j.matpr.2017.10.093.

[6] TKADLEČKOVÁ, M., WALEK, J., MICHALEK, K., HUCZALA, T. Numerical analysis of rtd curves and inclusions removal in a multistrand asymmetric tundish with different configuration of impact pad. Metals. [Online]. 2020, pp. 849. Available from: https://doi.org/10.3390/met10070849

[7] HUSSAIN, C, M. Nanomaterials in Chromatography: Current Trends in Chromatographic Research Technology and Techniques. Amsterdam: Elsevier, 2018.

[8] BUL'KO, B., KIJAC, J. Optimization of tundish equip-ment. Acta Metallurgica Slovaca. 2010, vol. 16, 2010, pp. 7683.

[9] GOK, K., INAL, S., GOK, A., GULBANDILAR, E. Orthogonal, Skewness quality mesh metrics spectrum. [Online]. 2017. [viewed: 2021-06-21]. Available from: https://www.researchgate.net/figure/Skewness-mesh-metricsspectrum fig4 316013451.

[10] BUL'KO, B., DEMETER, P. Laboratory of simulation of flow processes. Technical University of Košice, Institute of Metallurgy, Department of Metallurgy and Foundry. [Online]. 2017. [viewed: 2021-06-21]. Available from: https://ohaz.umet.fmmr.tuke.sk/lspp/index en.html. 